\title{
SENSITIVITY OF STREET NETWORK CAPACITY UNDER THE RAIN IMPACT: CASE STUDY OF BELGRADE
}

\author{
Ivan Ivanović, Jadranka Jović \\ Dept of Transportation Planning and Traffic Management, Faculty of Transport and Traffic Engineering, \\ University of Belgrade, Serbia
}

Submitted 5 May 2016; resubmitted 14 August 2016, 24 September 2016; accepted 5 November 2016; published online 12 April 2017

\begin{abstract}
It is generally know that adverse weather conditions cause changes in urban transportation system. Research of weather impact on the urban transportation system was additionally intensified by actualisation of climate changes problem. In urban area, precipitation may reduce the efficiency of transportation systems, since it often results in larger travel times and higher congestion levels in street networks. Therefore, it is important to examine the impact of precipitation on the urban street capacity. In accordance with climate characteristics of research area, the focus of this paper was on the rain impact. Impact of rain was analysed only in the context of transport supply, and not of transport demand. Sensitivity of the street network capacity was chosen to represent transportation system supply. It was analysed through the changes in saturation flow rate under the rain. Results of the research have shown significant sensitivity of street network capacity on the rain impact. Moreover, the rain impact was quantified by the capacity sensitivity coefficients, which were implemented in procedure of capacity calculation.
\end{abstract}

Keywords: transportation planning; urban street network; rain impact; saturation flow; capacity.

\section{Introduction}

Balance between transport supply and transport demand is one of the objective functions in transportation planning process. Bearing in mind complexity of the task, all factors that may affect the balance, should be taken into account. Sensitivity of transport system under the different weather conditions is becoming very important in the times of severe climate changes. Every deviation from the Ideal Weather Conditions (IWC) could be categorised as adverse weather. Criteria for determining adverse weather conditions depend on geographic location of the analysed area and behaviour and habits of inhabitants'. The IWC, regarding traffic and transport, can be described as: no precipitation, dry roadway, visibility greater than $0.4 \mathrm{~km}$, and the wind speed lower than $16 \mathrm{~km} / \mathrm{h}$ (Kyte et al. 2001). As an additional criterion which is recommended for IWC is temperature above $10^{\circ} \mathrm{C}$ (Tsapakis et al. 2013).

Through the various researches, the impact of precipitation has mostly been analysed as one of the most important climate element. In urban area, precipitation has considerable influence on the change of traffic conditions. Changes in drivers' behaviour and reduced vehicle performances increase the level of street network congestion (Pisano, Goodwin 2004; Gillam, Wilhill 1992). The change in drivers' behaviour, which is reflected in change of speed, headways, different route choice, etc., as consequences of an individual reaction, directly affects performances of the entire transportation system (Hranac et al. 2006; Petrovic et al. 2015). Users of transportation system adjust their behaviour to climate characteristics of area where they live.

Urban street network capacity can be observed through the link capacity and the intersection capacity. Most models for the calculation of signalised intersection capacity, i.e. traffic lane capacity, are based upon the calculations of the saturation flow rate. Saturation flow rate represents the hourly rate at which previously queued vehicles can traverse an intersection approach under prevailing conditions, assuming that the green signal is available at all times and no lost times are experienced, in vehicles per hour or vehicles per hour per lane (Highway Capacity Manual 2000). In signalised intersections modelling, the saturation flow represents a fundamental parameter of crucial importance (Asamer, Van Zuylen 2011; Teply et al. 1995). 
It is known that the adverse and extreme weather conditions affect transportation system performance, particularly in densely populated areas. Despite that, the consequences of climate change and weather conditions impacts on transport system, have not yet received the necessary attention in the literature - Koetse and Rietveld (2009); Böcker et al. (2013), etc. Consequently, the link between weather conditions and traffic flow parameters is still weak in the existing analytic tools. Reasons for this are recognized in modest simultaneous databases of traffic parameters as well as in weather characteristics.

The idea of this paper is to examine the rain impact on saturation flow rate at signalised intersection and to quantify it. Belgrade, the capital of the Republic of Serbia, was chosen for research. City with the population of over 1.5 million of residents and developed transportation system, this city has very intense traffic loads during peak periods (Jović, Đorić 2010). Furthermore, according to climate characteristics of the area in which this research was done, by frequency of occurrence rain stands out as the most appropriate parameter for a weather impact analysis. The usual phenomenon in Belgrade during the rain is the increased level of street network congestion. The quantification of rain impact represents the first step in the adaptation of traffic management process through improving traffic assignment procedures.

In the first section of the paper, the literature review of weather impact on transportation system supply is presented. The second section of the paper contains the research methodology, which in detail explains the collecting data method on weather conditions and saturated flow rate. Subsequently, the analysis and results of established correlation between the two mentioned databases is shown. In conclusion, the significance of obtained results is presented, as well as possibilities and limitations of applied methodology. Moreover, the directions for further research are defined.

\section{Literature Review}

Previous researches regarding the sensitivity of traffic flow parameters to weather impact are more oriented towards non-urban motorway and highway sections. The research results of weather impact on the traffic flow characteristics, led to the conclusion that leaving out weather conditions and visibility as significant factors in the procedures of determining capacity, represents deficiency (Moskowitz, Newman 1963). As stated, the first researches were based on the adverse weather impact of highway sections capacity. The estimated rain impacts on the capacity reduction ranged respectively from 8 to 19\% (Kleitsch, Cleveland 1971; Ries 1981; Jones, Goolsby 1970). In Highway Capacity Manual (2000), the recommendations for the assessment of adverse weather impacts on speed and capacity are based on two papers. It was concluded that high intensity rain affected the change in capacity from 14 to $15 \%$ and the change in free flow speed from 2 to $10 \mathrm{~km} / \mathrm{h}$, depend- ing on rain intensity (Ibrahim, Hall 1994). Brilon and Ponzlet (1996) concluded that the reduction of capacity ranges from 12 to $47 \%$, taking into account driving in high intensity rain during the night. One of the main reason of improved weather impact assessment in Highway Capacity Manual (2010) is that the results used in Highway Capacity Manual (2000) are from researches made in Canada and Germany, not in the US. Differences in technical characteristics of roads and drivers' behaviour have caused similar survey in the US in order to get better estimates (Agarwal et al. 2005).

Parameters, which are most frequently used in the analysis of urban traffic flows characteristics, are saturation flow and time delay. In the following literature review is presented the analysis of the change in the saturation flow rate under the rain impact. Gillam and Wilhill (1992) carried out the research on the weather impact on saturation flow rate in four urban areas in Great Britain. The results of the research showed that the saturation flow rate for a wet roadway decreased by $6 \%$, while time delay increased by $11 \%$ (Gillam, Wilhill 1992). Bernardin Lochmueller \& Associates analysed the traffic network of 24 signalised intersections in Anchorage, in order to improve traffic management in the winter season. The results showed that the saturation flow rate in the winter season, depending on the road characteristics, was reduced from 11 to $15 \%$ (BLA 1995). Researches carried out in Seoul, South Korea, showed that the reduction of saturation flow rate under the rain impact ranges from 4 to 13\% (Shin, Choi 1998). In that case the rain intensity was not considered. In Salt Lake City, the region with the intensive winter season, researches on the influence of weather conditions were conducted at two intersections (Perrin et al. 2001). The research period included 14 days with different weather conditions. The decrease in free flow speed ranged from 10 to $30 \%$, depending on type of the analysed weather conditions (from rain to slushy paths and wheel road surfaces condition) while the decrease of the saturation flow rate ranged from 6 to $20 \%$ (from rainy to snowy and sticking road surfaces condition). A research on the adverse weather impact at a signalised intersection in Burlington (Vermont) was aimed at examining the adverse weather impact on traffic flow characteristics, taking into consideration the longitudinal inclination on one of the intersection legs (Agbolosu-Amison et al. 2004). The results showed that under the precipitations there was a lower impact on the saturation flow rate reduction at the intersection leg with inclination (4\%), in comparison with intersection leg without inclination (7\%).

A research carried out in three cities in Poland has had the aim to assess the variability of the saturation flow rate at a signalised intersection, during the congestion period (Chodur et al. 2011). The variable used for analysing changes in the saturation flow rate was the state of weather conditions. The identified values of the relative reduction of the saturation flow rate ranged from 8.5 to $12.3 \%$ in the conditions of the long-term rain. For the short-term rain, this value was close to $3.6 \%$. Authors found that higher transport demand and 
a longer intersection queue affect the higher base rate of the saturation flow, as a consequence of the more dynamic drivers' behaviour. Sisiopiku and Sullivan (2011) published the results of a research of the rain impact, as the most common form of inclement weather, on the traffic flow characteristics in Birmingham. The aim was to examine the efficiency of signal plans under the rain impact. The saturation flow rate reduction under the low rain intensity ranged from $0 \%$ to $4 \%$, while for the medium rain intensity the saturation flow rate decreased from 3 to 9\%. Asamer and Van Zuylen (2011) conducted a research of various weather conditions impacts on the saturation flow rate at three intersections, in Vienna. The results showed that rain definitely affects the saturation flow rate. The identified decrease of the saturation flow rate for low intensity precipitation and wet surface ranged from 3 to $8.8 \%$, while in the case of high intensity participation it decreased from 1.5 to $14.8 \%$.

Unlike most aforementioned papers, within which the saturation flow rate for the straight traffic lane was examined, a research on the saturation flow at an intersection in Shanghai was based on the analysis of two protected left turn traffic lanes (Xu et al. 2013). The results showed that during rain saturation flow rate in both traffic lanes decrease from 3 to $7 \%$, while the increase in start-up delay, ranges from 21 to $33 \%$ compared to dry weather. When it comes to the location of the traffic lane, statistically significant differences in relation to the changes in the analysed parameters were not determined.

Previous research results show the existence of the rain impact on the saturation flow rate in the urban street network. Differences in the obtained results suggest locally specific character of the influence quantity, which results in the necessity to undertake the research at the specific area. Researches are mostly realized on urban arterial roads.

\section{Research Methodology}

The research methodology consists of three parts:

- classification of typical rain types for the research area, based on database of rain characteristics;

- selection of research locations according to set of criteria that provide minimization of other potential impact on saturation flow rate, besides rain;

- headways data collection.

It was very important to form high quality database of headways, according to previous rain type classification. Specific methodology for relevant headway determination is developed and applied for saturation flow calculation.

\subsection{Classification of Typical Rain Types for the Research Area}

According to Köppen-Geiger climate classification, the research area belongs to the zone of humid continental climate (Peel et al. 2006). In general, seasons in Belgrade are characterised by warm summers and mod- erately cold winters. The average annual temperature is around $11.4{ }^{\circ} \mathrm{C}$. The average annual precipitation is around $680 \mathrm{~mm}$, and the greatest share of precipitation occurs in May and June. The average annual number of days with precipitation is around 139 (38\%). Number of snowy days in recent years significantly declining, and rain represents the most common type of adverse weather conditions.

For better cognition of rain intensity characteristics, the rain intensity data were collected from Automatic Meteorological Station (AMS) in the period of the previous four years, i.e. from 2012 to 2015. The data on the rain intensity were collected at one-minute intervals and afterwards expanded to one-hour level. The total of 2063 hours with different rain intensity was recorded, which is approximately $5.8 \%$ of the total number of hours. In accordance with climate characteristics of the research area, low intensity rain takes the highest participation. High intensity rain is a characteristic of summer months, but mostly it is a very rare and short-term phenomenon. The basic idea of this rain database was to determine the typical rain intensity for the research area. Therefore, the impact of extreme adverse weather conditions (like rainstorm) with a low probability of occurrence at analysed area is not taken into account.

Rain categorisation in all previously mentioned scientific papers was related exclusively to the rain intensity (Wang et al. 2006; Asamer, Van Zuylen 2011; Highway Capacity Manual 2010). Bearing in mind the objective of this research, rain categorization will also take into account the frequency of rain with certain intensity. The idea was to analyse changes in saturation flow rate under the rain intensity that are typical for analysed area. Very rarely, optimization and modelling within the transportation system are done for extreme scenarios, i.e. for scenarios with very low probability of occurrence.

According to the experience of previous research (Smith et al. 2004; Highway Capacity Manual 2010), it was decided that rain categorisation include three categories. A large number of categories would significantly affect the complexity of research. $K$-means statistical method was used for categorisation in order to determine relatively homogeneous group of elements (Hartigan 1975). Within 2063 rainy hours, the distribution of various rain intensities was established (e.g. the level of presence for rain intensity of $0.5 \mathrm{~mm} / \mathrm{h}$ was $14.06 \%$ ). The value of the rain intensity ( $x$-axis) and its level of presence in totally recorded rainy hours ( $y$-axis) were presented as elements in coordinate system. The similarity of elements is determined by the Euclidean distance. In this case, $K$-means algorithm groups $n$ elements into three clusters in which each element belongs to the cluster whose center (arithmetic mean of cluster elements) is closest to the given element. Objective function that should be minimized represents the sum of all distances between elements and centres of corresponding clusters. Applied method provides that each element belongs to only one cluster and that each of the analysed elements must be assigned to a cluster. 


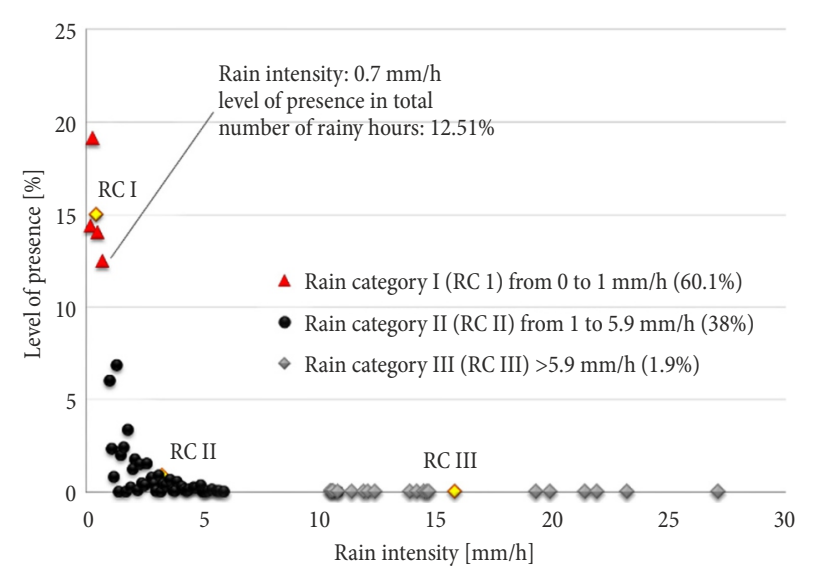

Fig. 1. Rain types classification

The results are shown in the following graph (Fig. 1). The graph shows three rain categories with the level of presence for each category in [\%].

For the validation of the clustered data 'Silhouette' method was applied, which indicates the quality of the defined clusters. The output value of the validation method can range from 1 (for well grouped cluster elements) to -1 (for poorly grouped cluster elements). The obtained value of 0.73 confirms the well grouped cluster elements.

As shown on the chart, the level of presence for elements belonging to Rain Category III (RC III) is rather small (from $0.1 \%$ for the rain intensity of $10.5 \mathrm{~mm} / \mathrm{h}$ to $0.05 \%$ for rain intensity of $27.1 \mathrm{~mm} / \mathrm{h}$ ). Because of low presence of RC III in researched area, this category will be excluded from further analysis.

\subsection{Selection of Research Locations}

In the research, the intersection selection criteria were such that the intersection characteristics and traffic flow characteristics at intersection provided isolated analysis of rain impact on saturation flow. In that way, all other potential impacts were minimised. The methodology implies that the research area had to meet the set of main and additional criteria.

The main criteria: intersection had to be located near to AMS due to accurate perception of meteorological data and had to be equipped with video monitoring. The process of intersections video monitoring in Belgrade is in development and exists on a small number of signalized intersections. Based on the main criteria, four signalized intersections are chosen, assuming that it will be possible to get an impression of rain impact characteristics.

Traffic lanes on those intersections had to satisfy the additional criteria: vehicle queue is formed in the analysed traffic lane; there is an undisturbed realisation of the queue discharge, queue from the upstream intersection does not have any impact on the vehicles leaving the entry under analysis; number of entry traffic lanes equals the number of exit traffic lanes; intersection has good technical characteristics (good condition of road surface, and traffic signalisations) and standard geometry (angle of intersection lags should be approximately 90 degrees allowing the straight trajectory of movement); there are no parking manoeuvres and bus stops in the intersection area; there is a minimal number of public transportation vehicles and commercial vehicles in the traffic flow composition.

In accordance with literature, intersections were located on major urban streets with high traffic volume. Two intersections were located in the inner city area, while the other two were positioned on the edge of the inner city area. Through video recordings, using special software, the vehicle headways during the queue discharge in the intersections, were registered.

\subsection{Headways Data Collection}

Traffic flow data were collected from video monitoring system. Recordings were used to determine the saturation flow, by using methodology that involved headways analysis of successive vehicles in the process of queue discharge. The headways were established based on the moment of the vehicle's rear axis passing over the stop line.

As mentioned before, rain data were collected in the period from 2012 to 2015 and used for rain categorisation. Researches of saturation flow were conducted during the rainy peak hours in 2015. Those hours were also part of database, which was used for rain categorisation. Research of saturation flow rate in peak hours, under the IWC, was mostly carried out during 2016. IWC were characterized by dry road surface, without precipitation, good visibility conditions and a temperature between 9 and $16^{\circ} \mathrm{C}$.

Within the peak hours, 1351 cycles in total were recorded, in different weather conditions. The cycles, which contained commercial or public transport vehicles in the queue, were eliminated from the total sample. Moreover, cycles within which unconscionable driver behaviour or some vehicle problem were identified, were eliminated too. In this way, a database of 1063 cycles was created (Table 1).

Table 1. Analysed weather types and sample of cycles per locations

\begin{tabular}{|c|c|c|c|c|c|c|c|}
\hline \multicolumn{4}{|c|}{ Edge of the inner city area } & \multicolumn{4}{c|}{ Inner city area } \\
\hline \multicolumn{2}{|c|}{ Location I } & \multicolumn{2}{c|}{ Location II } & \multicolumn{2}{c|}{ Location III } & \multicolumn{2}{c|}{ Location IV } \\
\hline $\begin{array}{c}\text { Weather } \\
\text { type }\end{array}$ & $\begin{array}{c}\text { Number } \\
\text { of cycles }\end{array}$ & $\begin{array}{c}\text { Weather } \\
\text { type }\end{array}$ & $\begin{array}{c}\text { Number } \\
\text { of cycles }\end{array}$ & $\begin{array}{c}\text { Weather } \\
\text { type }\end{array}$ & $\begin{array}{c}\text { Number } \\
\text { of cycles }\end{array}$ & $\begin{array}{c}\text { Weather } \\
\text { type }\end{array}$ & $\begin{array}{c}\text { Number } \\
\text { of cycles }\end{array}$ \\
\hline IWC & 105 & IWC & 91 & IWC & 100 & IWC & 83 \\
\hline RC I & 98 & RC I & 89 & RC I & 111 & RC I & 100 \\
\hline RC II & 72 & RC II & 74 & RC II & 71 & RC II & 69 \\
\hline
\end{tabular}




\subsection{Determination of Representative Headways for Saturation Flow Calculation}

When it comes to determination of the particular vehicle in the queue, from which the analysis of headways should start, different methodologies can be found in the literature. Perrin et al. (2001) stated several different examples: in Highway Capacity Manual (2000) the recommendation is to start headways analysis after the fourth vehicle, Korean Highway Capacity Manual recommend after the sixth vehicle and some authors recommend after the third vehicle (Shin, Choi 1998). None of the above-mentioned methodology does not considered the first few vehicles in the queue. In all cases, saturation flow rate is calculated through the average value of headway for determined set of vehicles (3600/average value of headway). Additionally, in all mentioned methodologies regardless of different criteria for vehicle positions from which the headways analysis should start, all of the remaining vehicles in the queue are taken into account.

Researches have shown that the cases of stabilised (constant trend of its change) queue discharge are extremely rare. Thus, in order to obtain more precise results, regarding the sensitivity of saturation flow changes under the different rain impacts, it is proposed to determine the relevant set of vehicles for the calculation of saturation flow rate. Relevant set of successive vehicles is characterized by relatively uniform headways.

Every sample of recorded headways on each location under the analysed weather types has been subjected to distribution normality testing, using KolmogorovSmirnov and Shapiro-Wilk tests. It was determined that in none of the analysed cases, headways have normal distribution. Hence, in order to increase the level of reliability, vehicle headway was obtained through the calculation of average values and medians.

In order to determine the relevant set of vehicles, the nonparametric Mann-Whitney $U$ test was used. This technique is used to test for differences between two independent groups on a continuous measure (Mann, Whitney 1947). In this case, the headways of successive vehicles represent the groups for comparison. For exam- ple, in assessing difference between headways of third and fourth vehicle in the queue, vehicles should be divided into two groups. First group would be composed of all recorded headways of third vehicles and second group would be composed of all recorded headways of fourth vehicles. This test converts the scores on the continuous variable to ranks across the two groups and then evaluates whether the ranks for the two groups differ significantly.

Fig. 2 shows the procedure of determining the relevant set of vehicles for the calculation of saturation flow rate for Location 1 in case of IWC.

According to obtained headway data, the chart shows changes of the average rates and medians of the saturation flow for each of the vehicles in the queue (line chart). The first vehicle was left out from the saturation flow rate analysis because of very frequent occurrence of the aggressive starts of first vehicle drivers in the queue.

The results of the application of the Mann-Whitney $\mathrm{U}$ test are also shown at the Fig. 2 (bar chart). The level of headway similarity for successive vehicle pairs is presented on the bar chart. The $p$-value of Mann-Whitney $\mathrm{U}$ test was used to determine the level of headways similarity. Looking at the figure, maximum number of vehicles in the recorded cycles was 17, but for the relevant set vehicle positions from 5 to 14 were accepted. The largest oscillations of $p$-value are seen after pair $4 \& 5$ ( $p$-value significantly increase) and after pair $13 \& 14$ ( $p$-value significantly decrease). Minimum $p$-value for relevant set of vehicles in this case was 0.38 . At the level of the whole sample for this case, the average value and median of the headways were calculated from the 5-th to the 14-th vehicle. Based on that headway value, saturation flow rate was calculated.

In relation to the analysed locations and weather type, it was not possible to establish a uniform criterion for the $p$-value, above which the vehicle in the queue fulfilled the requirement to be part of relative set of vehicles. Depending on the location and weather type, minimum $p$-value for relevant set of vehicles ranged from 0.38 to 0.64 . In this methodology, it was crucial to iden-



Fig. 2. Procedure of determining the relevant set of vehicles 
tify between which vehicles in the queue a significant oscillation in the $p$-values occurs.

In each of the previously mentioned methodologies (Highway Capacity Manual 2000; Shin, Choi 1998), for determining the saturation flow rate, the main criterion was to establish the average value of the headway, for part of vehicles, which reflects relatively uniform queue discharge. Mann-Whitney U test, by identifying the first and the last vehicle of relevant set of vehicles, complements that criterion.

\section{Results of the Research}

The calculation of saturation flow rate in relation to defined types of weather conditions was conducted, based on the developed methodology. The calculation results are shown in Table 2.

The obtained results show significant sensitivity of saturation flow rate under the rain impact. In both cases, when the calculation procedure is done through average values, as well as with medians, the reductions are noticeable in relation to the saturation flow rate determined for IWC. Based on methodology each intersection was analysed separately. The results of the average value of headways shows that the saturation flow rate reduction under the impact of RC I compared to IWC, ranges from 3 to $5.6 \%$. In the case of median, the reduction ranges from 2.2 to $5.8 \%$. When it comes to the impact of RC II, the average values shows that the reduction ranges between 7.7 and $11.9 \%$, while the median reduction ranges from 8.6 to $11.5 \%$. Comparing the each analysed scenario, the saturation flow rate obtained by median is slightly higher than the rate obtained by the analysis of the average values. In relation to the purpose of this research, the differences cannot be considered as significant.

By the comparison of obtained results, it is not possible to make some concrete conclusions, regarding the influence of intersection location on capacity decrease. In IWC, the obtained values of saturation flow rate were higher at the intersections in the inner city area, when compared to the intersections on the edge of the inner city area. Differences are not large, and can be attributed to the different technical characteristics of intersections (number of traffic lanes on the intersection approach, the size of intersections, signal plan etc.) rather than to the intersections location. When it comes to the rain im- pact on the saturation flow rate, based on the obtained results, it is also difficult to determine correlation according to intersections location.

The calculation of traffic lane capacity at signalised intersection may be stated as (Webster, Cobbe 1966):

$$
K=S \cdot \frac{g}{C},
$$

where: $K$ - traffic lane capacity [veh/h]; $S$ - saturation flow [vphgpl]; g - effective green time [s]; $C$ - cycle length [s].

However, taking into account the results of this research, a capacity sensitivity coefficient should be implemented in the presented equation. In this case, the capacity sensitivity coefficients are indicated by $\alpha_{1}$ (under the impact of RC I) and $\alpha_{2}$ (under the impact of RC II). Depending on the weather conditions under which the capacity would be calculated, the standard form would be modified to:

$$
K=\left(\alpha_{1}, \alpha_{2}\right) \cdot S \cdot \frac{g}{C},
$$

where: $\alpha_{1}$ - capacity sensitivity coefficient under the impact of RC I; $\alpha_{2}$ - capacity sensitivity coefficient under the impact of RC II.

Based on minimum and maximum values of capacity reduction, and not taking into account calculation method, it is calculated that the value of the $\alpha_{1}$ ranges from 0.978 to 0.942 , while the value of the $\alpha_{2}$ ranges from 0.923 to 0.881 . Since the rain categories were defined in the ranges, the capacity sensitivity coefficients were obtained in the ranges too.

\section{Conclusions}

It has been determined that the urban street network capacity is significantly sensitive to rain impact. It has also been shown that the intensity of the impact depends on the rain intensity.

Based on the research results, according to the analysed category of rain impact, the capacity sensitivity coefficients $\alpha_{1}$ (impact of rain category RC I) and $\alpha_{2}$ (impact of rain category RC II), were defined. The value of coefficient $\alpha_{1}$ ranges from 0.978 to 0.942 , while the value of coefficient $\alpha_{2}$ ranges from 0.923 to 0.881 . Therefore, traffic lane capacity can be determined as a product of sensitivity coefficients and the capacity, which is calculated under the IWC.

Table 2. Saturation flow rate reduction under the rain impact

\begin{tabular}{|l|l|c|c|c|c|c|c|c|c|}
\hline \multirow{2}{*}{} & \multirow{2}{*}{ Calculation method } & \multicolumn{2}{|c|}{ Location I } & \multicolumn{2}{c|}{ Location II } & \multicolumn{2}{c|}{ Location III } & \multicolumn{2}{c|}{ Location IV } \\
\cline { 3 - 12 } & & Median & Average & Median & Average & Median & Average & Median & Average \\
\hline \multirow{2}{*}{ IWC } & Saturation flow [vphgpl] & 2008 & 1968 & 1925 & 1885 & 2045 & 2034 & 2057 & 2023 \\
\hline \multirow{2}{*}{ RCI } & Saturation flow [vphgpl] & 1892 & 1860 & 1836 & 1827 & 1925 & 1920 & 2011 & 1949 \\
\cline { 2 - 11 } & Change [\%] & 5.8 & 5.5 & 4.6 & 3 & 5.8 & 5.6 & 2.2 & 3.7 \\
\hline \multirow{2}{*}{ RCII } & Saturation flow [vphgpl] & 1837 & 1809 & 1749 & 1739 & 1809 & 1791 & 1856 & 1837 \\
\cline { 2 - 11 } & Change [\%] & 8.6 & 8 & 9.1 & 7.7 & 11.5 & 11.9 & 9.8 & 9.2 \\
\hline
\end{tabular}

Note: vphgpl - unit for saturation flow rate ('vehicles per hour of green per lane'). 
In order to determine the value of capacity, special methodology was developed for calculation of saturation flow rate under the different weather types. The methodology was based on Mann-Whitney U test, which was used to identify the first and last vehicle of relevant set of vehicles in queue discharge process. For relevant set of vehicles, representative value of vehicle headway was established.

Most traffic models and tools used in the transportation planning and traffic management do not include parameters that indicate the weather impact, i.e. they are customised for IWC. It is therefore suggested to introduce the coefficient that describes sensitivity of capacity on rain impact. In areas with similar weather and driver behaviour characteristics, sensitivity coefficients obtained in this research could be used. Nevertheless, in situation where high precision of impact quantification is required (e.g. for traffic management purposes) the recommendation is to carry out particular research, in order to cover other characteristics of the research area.

Further researches will be directed towards the implementation of the rain impact into the transportation planning and traffic management models, with the focus on transport supply. It would involve more extensive researches on larger scale street network, greater number of intersections and weather data sources. In addition, further research should be focused on exploring the possibilities to adapt traffic management to the adverse weather conditions. It requires more detailed analysis comprising start-up delay, intersection size, type of signal control plan, distance between intersections, the influence of traffic composition etc.

\section{Acknowledgements}

This work was supported by the Ministry of Science and Technological Development of the Republic of Serbia.

\section{References}

Agarwal, M.; Maze, T. H.; Souleyrette, R. 2005. Impacts of weather on urban freeway traffic flow characteristics and facility capacity, in Proceedings of the 2005 Mid-Continent Transportation Research Symposium, 18-19 August 2005, Ames, Iowa, US, 1-14.

Agbolosu-Amison, S.; Sadek, A.; ElDessouki, W. 2004. Inclement weather and traffic flow at signalized intersections: case study from Northern New England, Transportation Research Record: Journal of the Transportation Research Board 1867: 163-171. https://doi.org/10.3141/1867-19

Asamer, J.; Van Zuylen, H. 2011. Saturation flow under adverse weather conditions, Transportation Research Record: Journal of the Transportation Research Board 2258: 103-109. https://doi.org/10.3141/2258-13

BLA. 1995. Anchorage Signal System Upgrade. Final report. Bernardin Lochmueller \& Associates (BLA), Evansville, Indiana.

Böcker, L.; Dijst, M.; Prillwitz, J. 2013. Impact of everyday weather on individual daily travel behaviours in perspective: a literature review, Transport Reviews 33(1): 71-91. https://doi.org/10.1080/01441647.2012.747114
Brilon, W: Ponzlet, M. 1996. Variability of speed-flow relationships on German autobahns, Transportation Research Record: Journal of the Transportation Research Board 1555: 91-98. https://doi.org/10.3141/1555-12

Chodur, J.; Ostrowski, K.; Tracz, M. 2011. Impact of saturation flow changes on performance of traffic lanes at signalised intersections, Procedia - Social and Behavioral Sciences 16: 600-611. https://doi.org/10.1016/j.sbspro.2011.04.480

Gillam, W. J.; Wilhill, R. A. 1992. UTC and inclement weather conditions, in Proceedings of the Institute of Electrical and Electronics Engineers Conference - Road Traffic Monitoring, IEE Conf. Pub. 355, April, 1992, United Kingdom, 85-88.

Hartigan, J. A. 1975. Clustering Algorithms. John Wiley \& Sons Inc. $366 \mathrm{p}$.

Highway Capacity Manual. 2010. Transportation Research Board. 5th edition. $1650 \mathrm{p}$.

Highway Capacity Manual. 2000. Transportation Research Board. 1134 p.

Hranac, R.; Sterzin, E.; Krechmer, D.; Rakha, H.; Farzaneh, M. 2006. Empirical Studies on Traffic Flow in Inclement Weather. Report No FHWA-HOP-07-073. Federal Highway Administration, Washington, DC, US. 108 p. Available from Internet: http://ops.fhwa.dot.gov/publications/weatherempirical/weatherempirical.pdf

Ibrahim, A. T.; Hall, F. L. 1994. Effect of adverse weather conditions on speed-flow-occupancy relationships, Transportation Research Record: Journal of the Transportation Research Board 1457: 184-191.

Jones, E. R.; Goolsby, M. E. 1970. The environmental influence of rain on freeway capacity, Highway Research Record 321: $74-82$.

Jović, J.; Đorić, V. 2010. Traffic and environmental street network modelling: Belgrade case study, Transport 25(2): 155162. https://doi.org/10.3846/transport.2010.19

Kleitsch, K.; Cleveland, D. 1971. The Effect of Rainfall on Freeway Capacity. HSRI Report No TrS-6. Highway Safety Research Institute, University of Michigan. $34 \mathrm{p}$.

Koetse, M. J.; Rietveld, P. 2009. The impact of climate change and weather on transport: an overview of empirical findings, Transportation Research Part D: Transport and Environment 14(3): 205-221. https://doi.org/10.1016/j.trd.2008.12.004

Kyte, M.; Khatib, Z.; Shannon, P.; Kitchener, F. 2001. Effect of weather on free-flow speed, Transportation Research Record: Journal of the Transportation Research Board 1776: 60-68. https://doi.org/10.3141/1776-08

Mann, H. B.; Whitney, D. R. 1947. On a test of whether one of two random variables is stochastically larger than the other, Annals of Mathematical Statistics 18(1): 50-60. https://doi.org/10.1214/aoms/1177730491

Moskowitz, K.; Newman, L. 1963. Notes on freeway capacity, Highway Research Record 27: 44-68.

Peel, M. C.; Finlayson, B. L.; McMahon, T. A. 2007. Updated world map of the Köppen-Geiger climate classification, Hydrology and Earth System Sciences 11(5): 1633-1644. https://doi.org/10.5194/hess-11-1633-2007

Perrin, H.; Martin, P.; Hansen, B. 2001. Modifying signal timing during inclement weather, Transportation Research Record: Journal of the Transportation Research Board 1748: 66-71. https://doi.org/10.3141/1748-08

Petrovic, D.; Ivanovic, I.; Djoric, V. 2015. Does weather impact on commuters' travel demand - empirical case study of Belgrade, in European Transport Conference 2015 (ETC 2015), 28-30 September 2015, Frankfurt, Germany, 1-11. 
Pisano, P. A.; Goodwin, L. C. 2004. Arterial operations in adverse weather, in ITE 2004 Annual Meeting and Exhibit Compendium of Technical Papers, 1-4 August 2004, Lake Buena Vista, Florida, US, 1-11.

Ries, G. L. 1981. Impact of Weather on Freeway Capacity. Minnesota Department of Transportation. Office of Traffic Engineering, Systems and Research Section. 40 p.

Shin, C.-H.; Choi, K. 1998. Saturation flow rate estimation under rainy weather conditions for on-line traffic control purpose, KSCE Journal of Civil Engineering 2(3): 211-222. https://doi.org/10.1007/BF02830476

Sisiopiku, V. P.; Sullivan, A. 2011. Impacts of signal system timings on rain related congestion, International Journal of Engineering and Industries 2(1): 1-12.

Smith, B. L.; Byrne, K. G.; Copperman, R. B.; Hennessy, S. M.; Goodall, N. J. 2004. An investigation into the impact of rainfall on freeway traffic flow, in TRB 83rd Annual Meeting Compendium of Papers CD-ROM, 11-15 January 2004, Washington, DC, US, 1-15.

Teply, S.; Allingham, D. I.; Richardson, D. B.; Stephenson, B.W. 1995. Canadian Capacity Guide for Signalized Intersections. Institute of Transportation Engineers, Canada. 115 p.

Tsapakis, I.; Cheng, T.; Bolbol, A. 2013. Impact of weather conditions on macroscopic urban travel times, Journal of Transport Geography 28: 204-211. https://doi.org/10.1016/j.jtrangeo.2012.11.003

Wang, L.; Yamamoto, T.; Miwa, T.; Morikawa, T. 2006. An analysis of effects of rainfall on travel speed at signalized surface road network based on probe vehicle data, in Proceedings of the Conference on Traffic and Transportation Studies (ICTTS), 2-4 August 2006, Xian, China, 1-9.

Webster, F. V.; Cobbe, B. M. 1966. Traffic Signals. London. Her Majesty's Stationery Office (HMSO). 198 p.

Xu, F.; He, Z.; Sha, Z.; Zhuang, L.; Sun, W. 2013. Assessing the impact of rainfall on traffic operation of urban road network, Procedia - Social and Behavioral Sciences 96: 82-89. https://doi.org/10.1016/j.sbspro.2013.08.012 